\title{
Anisotropic Thermal Expansion of Zirconium Diboride: An Energy-Dispersive X-Ray Diffraction Study
}

\begin{abstract}
William A. Paxton, ${ }^{1}$ Tevfik E. Özdemir, ${ }^{1}$ İlyas Savklıyıldız, ${ }^{1}$ Terence Whalen, ${ }^{1}$ Hülya Biçer, ${ }^{1}$ Enver Koray Akdoğan, ${ }^{1}$ Zhong Zhong, ${ }^{2}$ and Thomas Tsakalakos ${ }^{1}$
\end{abstract}

\author{
${ }^{1}$ Materials Science and Engineering, Rutgers, The State University of New Jersey, Piscataway, NJ 08854, USA \\ ${ }^{2}$ Photon Sciences, Brookhaven National Laboratory, Upton, NY 11973, USA
}

Correspondence should be addressed to William A. Paxton; will.paxton@rutgers.edu

Received 31 March 2016; Revised 10 May 2016; Accepted 12 May 2016

Academic Editor: Yuan-hua Lin

Copyright ( 2016 William A. Paxton et al. This is an open access article distributed under the Creative Commons Attribution License, which permits unrestricted use, distribution, and reproduction in any medium, provided the original work is properly cited.

\begin{abstract}
Zirconium diboride $\left(\mathrm{ZrB}_{2}\right)$ is an attractive material due to its thermal and electrical properties. In recent years, $\mathrm{ZrB} \mathrm{B}_{2}$ has been investigated as a superior replacement for sapphire when used as a substrate for gallium nitride devices. Like sapphire, $\mathrm{ZrB} \mathrm{B}_{2}$ has an anisotropic hexagonal structure which defines its directionally dependent properties. However, the anisotropic behavior of $\mathrm{ZrB}_{2}$ is not well understood. In this paper, we use energy-dispersive synchrotron X-ray diffraction to measure the thermal expansion of polycrystalline $\mathrm{ZrB}_{2}$ powder from 300 to $1150 \mathrm{~K}$. Nine Bragg reflections are fit using Pseudo-Voigt peak profiles and used to compute the $a$ and $c$ lattice parameters using a nonlinear least-squares approximation. The temperature-dependent instantaneous thermal expansion coefficients are determined for each $a$-axis and $c$-axis direction and are described by the following equations: $\alpha_{a}=\left(4.1507 \times 10^{-6}+5.1086 \times 10^{-9}(T-293.15)\right) /\left(1+4.1507 \times 10^{-6}(T-293.15)+2.5543 \times 10^{-9}(T-293.15)^{2}\right)$ and $\alpha_{c}=(4.5374 \times$ $\left.10^{-6}+4.3004 \times 10^{-9}(T-293.15)\right) /\left(1+4.5374 \times 10^{-6}(T-293.15)+2.1502 \times 10^{-9}(T-293.15)^{2}\right)$. Our results are within range of previously reported values but describe the temperature anisotropy in more detail. We show that anisotropic expansion coefficients converge to the same value at about $780 \mathrm{~K}$ and diverge at higher temperatures. Results are compared with other reported values.
\end{abstract}

\section{Introduction}

Zirconium diboride $\left(\mathrm{ZrB}_{2}\right)$ is a nonoxide ceramic material with a melting temperature of $3245^{\circ} \mathrm{C}$ and high electrical conductivity $\left(10^{7} \mathrm{~S} \cdot \mathrm{m}^{-1}\right)$ [1]. The ultrahigh melting temperature and resistance to oxidation of $\mathrm{ZrB}_{2}$ make the material attractive for applications in ultrasonic flight, continuous steel processing, and atmospheric reentry [1-3]. $\mathrm{ZrB}_{2}$ is also unique, however, for its electronic properties. Recently, single crystal $\mathrm{ZrB}_{2}$ has been used as a substrate for gallium nitride $(\mathrm{GaN})$ semiconductor devices $[4,5] . \mathrm{ZrB}_{2}$ has intrinsic advantages over sapphire, the industry standard. Notably, $\mathrm{ZrB}_{2}$ has a smaller lattice mismatch to $\mathrm{GaN}$ and superior electronic and thermal conductivity.

Proper use of $\mathrm{ZrB}_{2}$ in any application requires an indepth understanding of the thermal behavior. The crystal arrangement of $\mathrm{ZrB}_{2}$ is hexagonal with alternating layers of $\mathrm{Zr}$ and $\mathrm{B}$ atoms [1]. This hexagonal nature of $\mathrm{ZrB}_{2}$ leads to anisotropic behavior and properties which are crucial to understand, especially in applications where the crystal orientation of $\mathrm{ZrB}_{2}$ is controlled.

The thermal behavior of $\mathrm{ZrB}_{2}$ has been studied in the past. The pioneering work by Kinoshita and coworkers was able to show that $\mathrm{ZrB}_{2}$ is a viable substrate for $\mathrm{GaN}$ electronics. They grew single crystals of $\mathrm{ZrB}_{2}$ using a float zone method and measured the coefficient of thermal expansion along the $a$ direction $[4,5]$. Thermal expansion was later studied by Okamoto et al. where they grew single crystals in a similar manner and measured expansion in both the $a$ and $c$ directions using a pushrod-type dilatometer from room temperature to $1073 \mathrm{~K}$ [6]. Their results revealed the anisotropic nature of thermal expansion with average coefficient of thermal expansion (CTE) values of $6.66 \times 10^{-6}$ and $6.93 \times$ $10^{-6} \mathrm{~K}^{-1}$ in the $a$ and $c$ directions, respectively. They also showed that their values carry a temperature dependence, however. Zimmermann et al. used a densified polycrystalline 


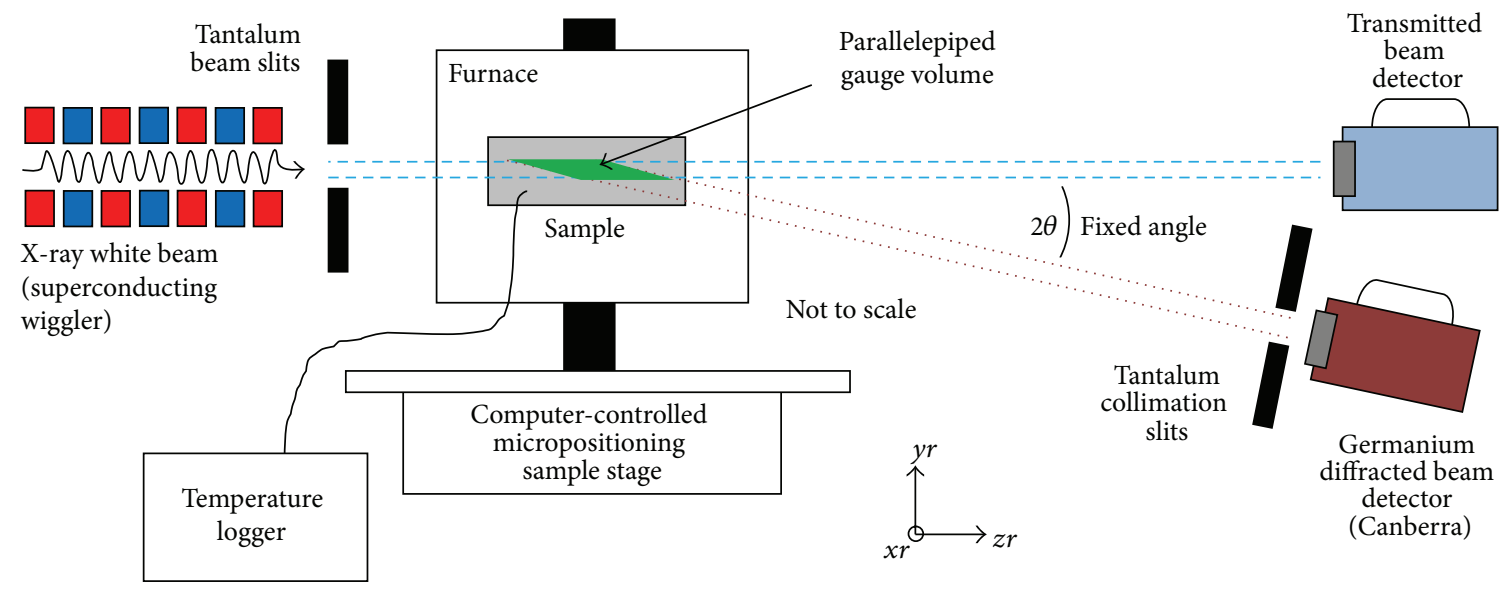

FIgURE 1: Schematic of the EDXRD experiment.

sample to study the thermal expansion of $\mathrm{ZrB}_{2}$ [7]. Their study employed the use of dilatometer and measured expansion from $300 \mathrm{~K}$ to $1675 \mathrm{~K}$. They were able to measure the temperature-dependent CTE but their polycrystalline sample means that they were insensitive to directional effects. The CTE of $\mathrm{ZrB}_{2}$ can also be calculated from first principles. Milman et al. performed a molecular dynamics study and calculated values of thermal expansion that were within range of previous reports. While they mention that Okamoto's results show anisotropy and temperature dependence, they were unable to address these features within their experimental framework [8].

Scattering techniques such as X-ray diffraction can measure the distance between planes of atoms in a crystal. Because of this, X-ray diffraction has been used extensively to measure thermal expansion [9-14]. Energy-dispersive X-ray diffraction is particularly well-suited for measuring changes in interatomic distances [15-19]. This is because unlike the more-common angular-dispersive X-ray diffraction, EDXRD satisfies the scattering condition with polychromatic radiation at a fixed angle. This enables one to make very precise lattice parameter measurements [10,20]. Additionally, the use of an energy-discriminating detector means that the entire spectrum is collected in parallel which is ideal for timeresolved measurements [21, 22].

In this paper, we take advantage of the penetrative power of synchrotron radiation and measure the thermal expansion of polycrystalline $\mathrm{ZrB}_{2}$ in situ up to $1100 \mathrm{~K}$. Particular focus is given to the anisotropic effects of $\mathrm{ZrB}_{2}$ 's hexagonal lattice and the temperature dependence of thermal expansion.

\section{Experimental}

Polycrystalline $\mathrm{ZrB}_{2}$ powder was obtained from $\mathrm{H}$. C. Stark Corporation (Grade B Hf min $0.2 \% \quad 90 \% \quad<6 \mu \mathrm{m}$ ). The powder was loosely packed in an alumina vessel and a type$\mathrm{K}$ thermocouple was placed in the center of the powder. The vessel was then placed in a furnace built for high temperature in situ diffraction work. The details of this furnace have been covered previously in the literature [21].
Energy-dispersive X-ray diffraction (EDXRD) was carried out at the National Synchrotron Light Source X17B1 beamline at Brookhaven National Laboratory. EDXRD uses a fixed angle and polychromatic radiation in order to satisfy the Bragg diffraction condition. As a result, the diffraction measurement works directly in reciprocal space and enables precise determination of the lattice parameters. The measurement volume is fixed in space and the spectra are collected in a parallel fashion. These factors of EDXRD make it a viable technique for in situ measurement of thermal expansion. Figure 1 shows the experimental configuration.

The sample was heated from room temperature to approximately $1150 \mathrm{~K}$ at a heating rate of $5 \mathrm{~K}$ per minute in an argon environment to prevent oxidation. Throughout the experiment, spectra were collected every 30 seconds. Additionally, the temperature was logged by the thermocouple every one second. The clocks on both the temperature logger and the EDXRD computer were synchronized so that the temperature and EDXRD data could be correlated.

Standards for calibration were collected from $\mathrm{Ag}, \mathrm{Au}$, $\mathrm{CeO}_{2}, \mathrm{Cu}, \mathrm{Ge}, \mathrm{LaB}_{6}, \mathrm{~W}$, and $\mathrm{Y}_{2} \mathrm{O}_{3}$ and used to determine the channel number to energy relationship and the exact angle of diffraction. Additionally, laboratory powder diffraction was carried out to characterize the powder and included in the calibration.

The 001, 100, 101, 002, 110, 102, 111, 200, and 201 peaks were identified in the spectra and were fit with Pseudo-Voigt peak-shape function [23]. The $d$-spacing for the nine peaks were then used to calculate the $a$ and $c$ lattice parameters using a nonlinear least-squares determination incorporating the Levenberg-Marquardt algorithm using the fsolve function in MATLAB.

\section{Results and Discussion}

Figure 2 shows the lattice parameter $a$ as a function of temperature and Figure 3 shows the lattice parameter $c$ as a function of temperature. The data show a minimal degree of scatter which should be considered a representation of the error in both the peak fitting and the temperature recording. 


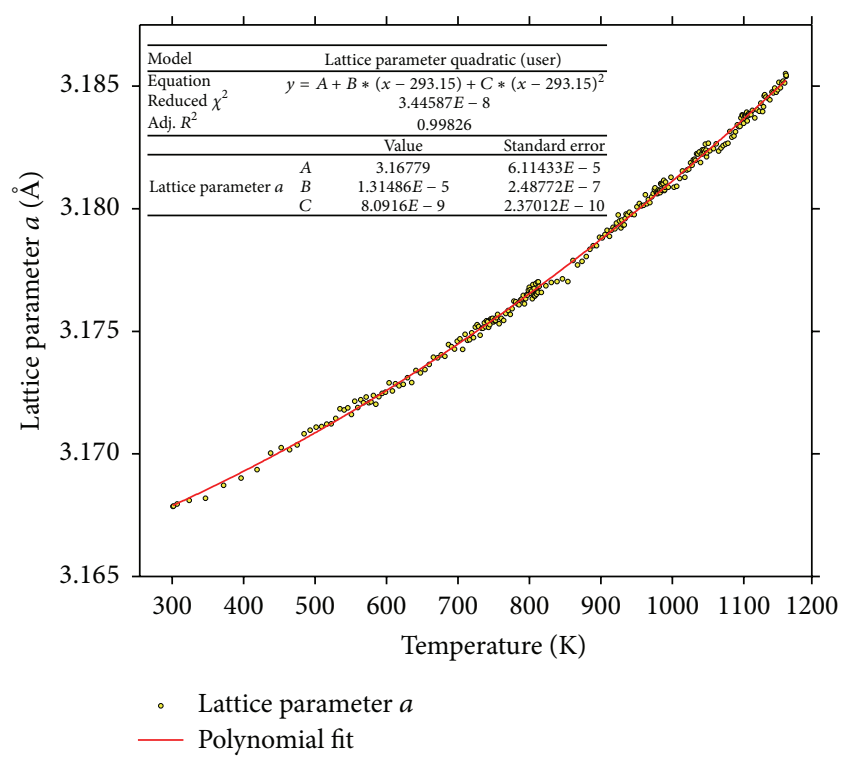

Figure 2: Lattice constant $a$ as a function of temperature.

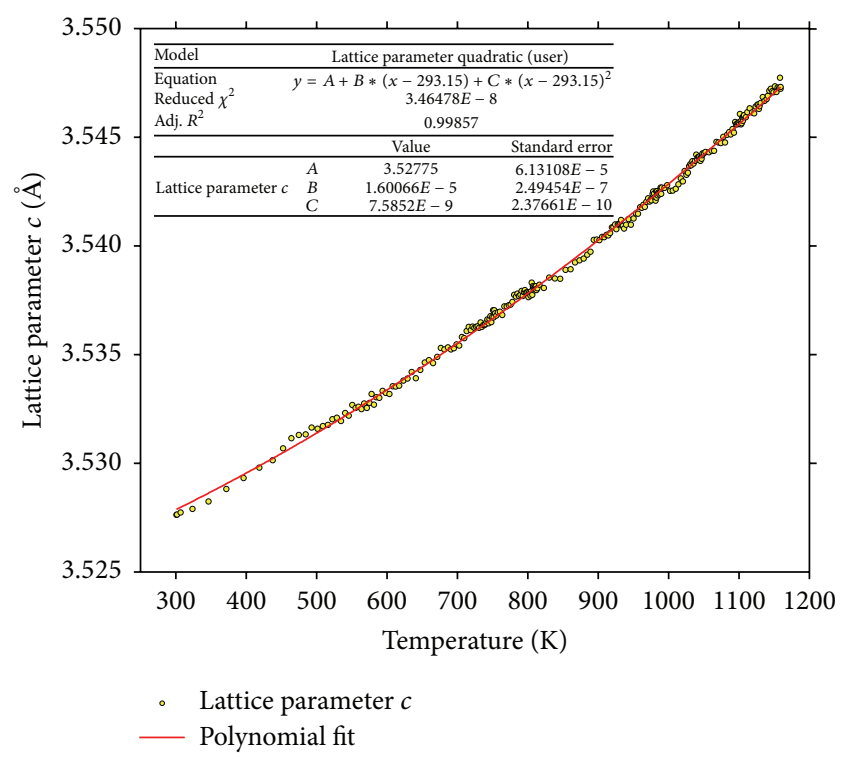

FIgURE 3: Lattice constant $c$ as a function of temperature.

Additionally, throughout the experiment we observe uniform thermal expansion and no structural changes.

The CTE can be expressed as

$$
\alpha=\frac{1}{l} \frac{d l}{d T},
$$

where $l$ is a length and $d l / d T$ is the rate of change of that length with temperature. Rearranging gives us

$$
\frac{\Delta l}{l}=\alpha \Delta T
$$

assuming that the expansion coefficient does not change with temperature. For small changes in temperature, this

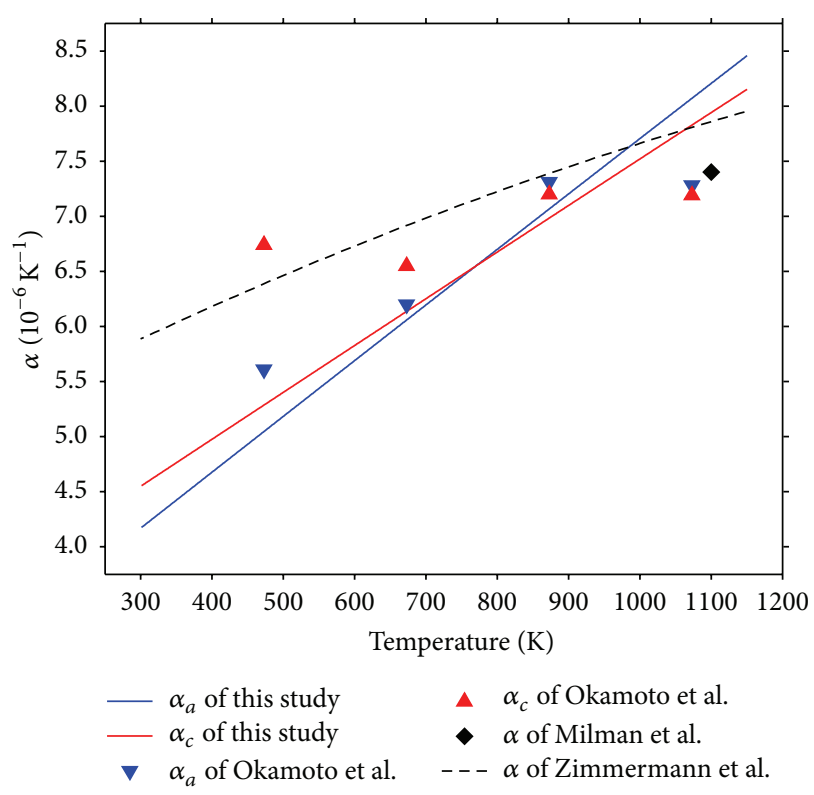

FIGURE 4: Temperature dependence of coefficient of thermal expansion.

provides a good approximation. However, this experiment deals with a temperature range of $850 \mathrm{~K}$, rendering the above approximation useless. The behavior of the lattice parameter over the given range of temperatures can be approximated using the following second order polynomial equation:

$$
a(T)=a_{o}+\alpha^{\prime}(T-\Theta)+\alpha^{\prime \prime}(T-\Theta)^{2},
$$

where $a$ is the lattice parameter, $T$ is the measured temperature, $\Theta$ is a reference temperature, $a_{o}$ is the lattice parameter at the reference temperature, and $\alpha^{\prime}$ and $\alpha^{\prime \prime}$ are the first- and second-order expansion coefficients, respectively.

The quadratic behavior of the lattice parameter with temperature results in a CTE that is linearly dependent on temperature. By taking the derivative of the fit equation and dividing by the lattice parameter, one can calculate the temperature-dependent instantaneous expansion coefficient $[24,25]$. This is shown in the following equation:

$$
\mathrm{CTE}=\alpha(T)=\frac{\alpha^{\prime}+2 \alpha^{\prime \prime}(T-\Theta)}{a_{o}+\alpha^{\prime}(T-\Theta)+\alpha^{\prime \prime}(T-\Theta)^{2}} .
$$

In both Figures 2 and 3, the lattice parameter data are fit with the second order polynomial equation and a reference temperature of $293.15 \mathrm{~K}$. The fitting results are given in Table 1. The fit is excellent with a coefficient of determination $\left(R^{2}\right)$ value greater than 0.998 for both lattice parameters.

The CTE dependence on temperature for both the $a$ and $c$ directions is shown in Figure 4. Additionally, selected values are given in Table 2. At room temperature, we observe anisotropic behavior with a larger CTE in the $c$ direction. The two lines converge around $780 \mathrm{~K}$, however, where at this temperature the CTE is isotropic. At temperatures greater than $780 \mathrm{~K}$, we observe a higher expansion in the $a$ direction. 


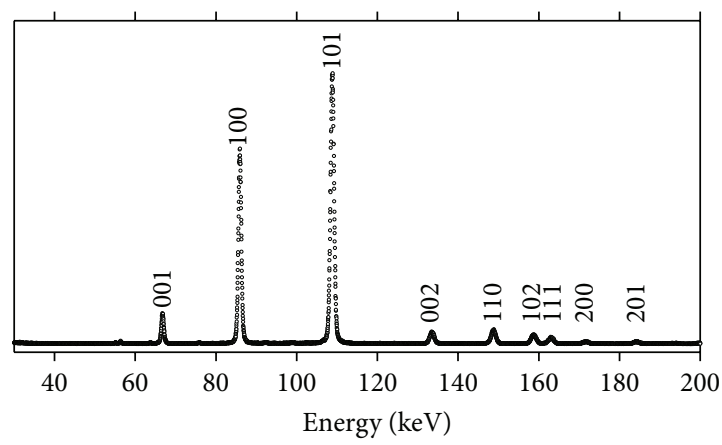

(a)

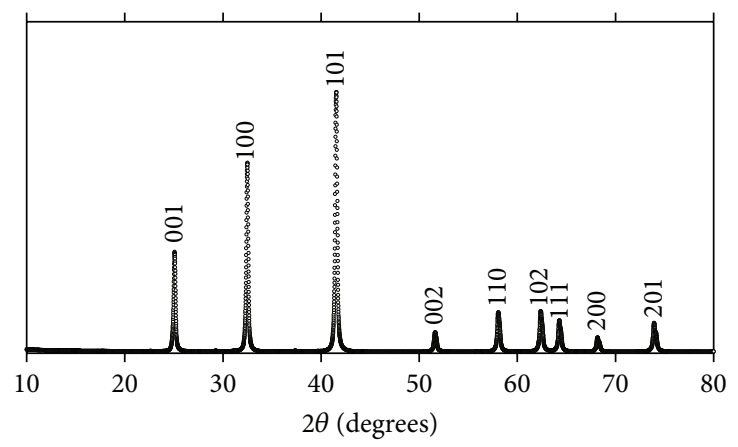

(b)

FIgURE 5: Diffraction patterns. (a) Energy-dispersive X-ray diffraction data at $300 \mathrm{~K}$. (b) Angular-dispersive X-ray diffraction data at $300 \mathrm{~K}$.

TABLE 1: Constants solved using the polynomial fit of lattice parameter versus temperature.

\begin{tabular}{lcccc}
\hline $\begin{array}{l}\text { Lattice } \\
\text { parameter }\end{array}$ & $\begin{array}{c}a_{o} \\
\AA\end{array}$ & $\alpha^{\prime}$ & $\alpha^{\prime \prime}$ & $R^{2}$ \\
\hline$a$ & $3.16779(6)$ & $1.314(25) \times 10^{-5}$ & $8.09(24) \times 10^{-9}$ & 0.9983 \\
$c$ & $3.52775(6)$ & $1.601(25) \times 10^{-5}$ & $7.59(24) \times 10^{-9}$ & 0.9986 \\
\hline
\end{tabular}

TABLE 2: Instantaneous values of expansion coefficient at selected temperatures.

\begin{tabular}{lcc}
\hline $\begin{array}{l}\text { Temperature } \\
\mathrm{K}\end{array}$ & $\begin{array}{c}\alpha_{a} \\
10^{-6} \mathrm{~K}^{-1}\end{array}$ & $\begin{array}{c}\alpha_{c} \\
10^{-6} \mathrm{~K}^{-1}\end{array}$ \\
\hline 300 & 4.17 & 4.55 \\
400 & 4.68 & 4.98 \\
500 & 5.19 & 5.41 \\
600 & 5.70 & 5.83 \\
700 & 6.20 & 6.26 \\
800 & 6.71 & 6.68 \\
900 & 7.21 & 7.10 \\
1000 & 7.71 & 7.52 \\
1100 & 8.21 & 7.95 \\
\hline
\end{tabular}

The calculated expression for the temperature-dependent instantaneous expansion coefficient is given below:

$$
\begin{aligned}
& \alpha_{a} \\
& =\frac{4.1507 \times 10^{-6}+5.1086 \times 10^{-9}(T-293.15)}{1+4.1507 \times 10^{-6}(T-293.15)+2.5543 \times 10^{-9}(T-293.15)^{2}}, \\
& \alpha_{c} \\
& =\frac{4.5374 \times 10^{-6}+4.3004 \times 10^{-9}(T-293.15)}{1+4.5374 \times 10^{-6}(T-293.15)+2.1502 \times 10^{-9}(T-293.15)^{2}} .
\end{aligned}
$$

There are some interesting differences when comparing our results with other values reported in the literature. CTE values from Okamoto et al., Zimmermann et al., and Milman et al. are plotted in Figure 4. For CTE values given with a range, they are plotted at their upper limit of the range. Above $650 \mathrm{~K}$, there is good agreement between our values and those reported by others. However, below $650 \mathrm{~K}$ our values are lower than those of Okamoto et al. Because this is within operating temperature range of a typical GaN LED, it is important to understand the results. It is well known for thermal expansion that lattice parameter measurements differ from macroscopic measurements. Particularly, our diffraction is not sensitive to the increases in thermodynamic defects associated with higher temperatures. Additionally, Okamoto et al. do not mention anything about the quality of their crystal, that is, whether or not there is significant twinning or other defects. These things could explain the significantly higher values they observe.

Figure 5 shows both the EDXRD and ADXRD spectra at room temperature. We see a good agreement between the two methods and observe no secondary phases. Whole pattern fitting was carried out on the ADXRD measurement and the lattice parameters were found to be within range of the literature values.

\section{Conclusion}

We performed energy-dispersive synchrotron X-ray diffraction measurements while heating a polycrystalline $\mathrm{ZrB}_{2}$ powder from 300 to $1150 \mathrm{~K}$. The temperature-dependent instantaneous thermal expansion coefficients were determined for the $a$-axis and $c$-axis directions. The results show that $\alpha_{a}$ and $\alpha_{c}$ converge to the same value at around $780 \mathrm{~K}$, below which $\alpha_{c}$ is higher and above which $\alpha_{a}$ is higher.

\section{Competing Interests}

The authors declare that they have no competing interests.

\section{Acknowledgments}

The authors acknowledge Bart Visser and Ankur Choksi for their support in the laboratory and helpful discussions. This research was supported by the Office of Naval Research Grant no. N00014-13-1-0164 entitled "Thermokinetic Origins of Sintering in Nanocrystalline Ceramics by In Situ High Temperature and Pressure Synchrotron Energy-Dispersive X-ray Diffraction.” 


\section{References}

[1] W. G. Fahrenholtz, G. E. Hilmas, I. G. Talmy, and J. A. Zaykoski, "Refractory diborides of zirconium and hafnium," Journal of the American Ceramic Society, vol. 90, no. 5, pp. 1347-1364, 2007.

[2] A. L. Chamberlain, W. G. Fahrenholtz, G. E. Hilmas, and D. T. Ellerby, "High-strength zirconium diboride-based ceramics," Journal of the American Ceramic Society, vol. 87, no. 6, pp. 11701172, 2004.

[3] A. L. Chamberlain, W. G. Fahrenholtz, and G. E. Hilmas, "Pressureless sintering of zirconium diboride," Journal of the American Ceramic Society, vol. 89, no. 2, pp. 450-456, 2006.

[4] H. Kinoshita, S. Otani, S. Kamiyama et al., "Zirconium diboride (0001) as an electrically conductive lattice-matched substrate for gallium nitride," Japanese Journal of Applied Physics, Part 2: Letters, vol. 40, no. 12, pp. L1280-L1282, 2001.

[5] H. Kinoshita, S. Otani, S. Kamiyama et al., " $\mathrm{ZrB}_{2}$ substrate for nitride semiconductors," Japanese Journal of Applied Physics, vol. 42, no. 4, pp. 2260-2264, 2003.

[6] N. L. Okamoto, M. Kusakari, K. Tanaka et al., "Temperature dependence of thermal expansion and elastic constants of single crystals of $\mathrm{ZrB}_{2}$ and the suitability of $\mathrm{ZrB}_{2}$ as a substrate for $\mathrm{GaN}$ film," Journal of Applied Physics, vol. 93, no. 1, article 88, 2003.

[7] J. W. Zimmermann, G. E. Hilmas, W. G. Fahrenholtz et al., "Thermophysical properties of $\mathrm{ZrB}_{2}$ and $\mathrm{ZrB}_{2}-\mathrm{SiC}$ ceramics," Journal of the American Ceramic Society, vol. 91, no. 5, pp. 14051411, 2008.

[8] V. Milman, B. Winkler, and M. I. J. Probert, "Stiffness and thermal expansion of $\mathrm{ZrB}_{2}$ : an ab initio study," Journal of Physics: Condensed Matter, vol. 17, no. 13, pp. 2233-2241, 2005.

[9] J. W. Edwards, R. Speiser, and H. L. Johnston, "High temperature structure and thermal expansion of some metals as determined by X-ray diffraction data. I. Platinum, tantalum, niobium, and molybdenum," Journal of Applied Physics, vol. 22, no. 4, pp. 424-428, 1951.

[10] B. Buras, J. S. Olsen, L. Gerward, G. Will, and E. Hinze, "X-ray energy-dispersive diffractometry using synchrotron radiation," Journal of Applied Crystallography, vol. 10, no. 6, pp. 431-438, 1977.

[11] T. A. Mary, J. S. O. Evans, T. Vogt, and A. W. Sleight, "Negative thermal expansion from 0.3 to 1050 Kelvin in $\mathrm{ZrW}_{2} \mathrm{O}_{8}$," Science, vol. 272, no. 5258, pp. 90-92, 1996.

[12] A. H. Chin, R. W. Schoenlein, T. E. Glover, P. Balling, W. P. Leemans, and C. V. Shank, "Ultrafast structural dynamics in InSb probed by time-resolved X-ray diffraction," Physical Review Letters, vol. 83, no. 2, pp. 336-339, 1999.

[13] K. A. Udachin, C. I. Ratcliffe, and J. A. Ripmeester, "Structure, composition, and thermal expansion of $\mathrm{CO}_{2}$ hydrate from single crystal X-ray diffraction measurements," Journal of Physical Chemistry B, vol. 105, no. 19, pp. 4200-4204, 2001.

[14] Y. Maniwa, R. Fujiwara, H. Kira et al., "Thermal expansion of single-walled carbon nanotube (SWNT) bundles: X-ray diffraction studies," Physical Review B, vol. 64, no. 24, Article ID 241402, 2001.

[15] M. Croft, I. Zakharchenko, Z. Zhong et al., "Strain field and scattered intensity profiling with energy dispersive X-ray scattering," Journal of Applied Physics, vol. 92, no. 1, pp. 578-586, 2002.

[16] M. Croft, Z. Zhong, N. Jisrawi et al., "Strain profiling of fatigue crack overload effects using energy dispersive X-ray diffraction," International Journal of Fatigue, vol. 27, no. 10-12, pp. 1408-1419, 2005.
[17] J. Rijssenbeek, Y. Gao, Z. Zhong et al., "In situ X-ray diffraction of prototype sodium metal halide cells: time and space electrochemical profiling," Journal of Power Sources, vol. 196, no. 4, pp. 2332-2339, 2011.

[18] W. A. Paxton, Z. Zhong, and T. Tsakalakos, "Tracking inhomogeneity in high-capacity lithium iron phosphate batteries," Journal of Power Sources, vol. 275, pp. 429-434, 2015.

[19] W. A. Paxton, E. K. Akdoğan, İ. Şavkliyildiz et al., "Asynchronous stoichiometric response in lithium iron phosphate batteries," Journal of Materials Research, vol. 30, no. 3, pp. 417423, 2015.

[20] E. K. Akdoğan, I. Şavklıyıldız, H. Biçer et al., "Anomalous lattice expansion in yttria stabilized zirconia under simultaneous applied electric and thermal fields: a time-resolved in situ energy dispersive X-ray diffractometry study with an ultrahigh energy synchrotron probe," Journal of Applied Physics, vol. 113, no. 23, Article ID 233503, 2013.

[21] B. Kämpfe, F. Luczak, and B. Michel, "Energy dispersive X-ray diffraction," Particle \& Particle Systems Characterization, vol. 22, no. 6, pp. 391-396, 2006.

[22] W. A. Paxton, In-situ and operando characterization of batteries with energy-dispersive synchrotron $X$-ray diffraction [Ph.D. thesis], Rutgers University-Graduate School-New Brunswick, New Brunswick, NJ, USA, 2015.

[23] M. Wojdyr, "Fityk: a general-purpose peak fitting program," Journal of Applied Crystallography, vol. 43, no. 5, pp. 1126-1128, 2010.

[24] D. Harris, Materials for Infrared Windows and Domes: Properties and Performance, vol. PM70 of SPIE Press Monograph, Society of Photo Optical, 1999.

[25] S. Bagdade and ASM, ASM Ready Reference: Thermal Properties of Metals (Materials Data Series), ASM International, Novelty, Ohio, USA, 2002. 

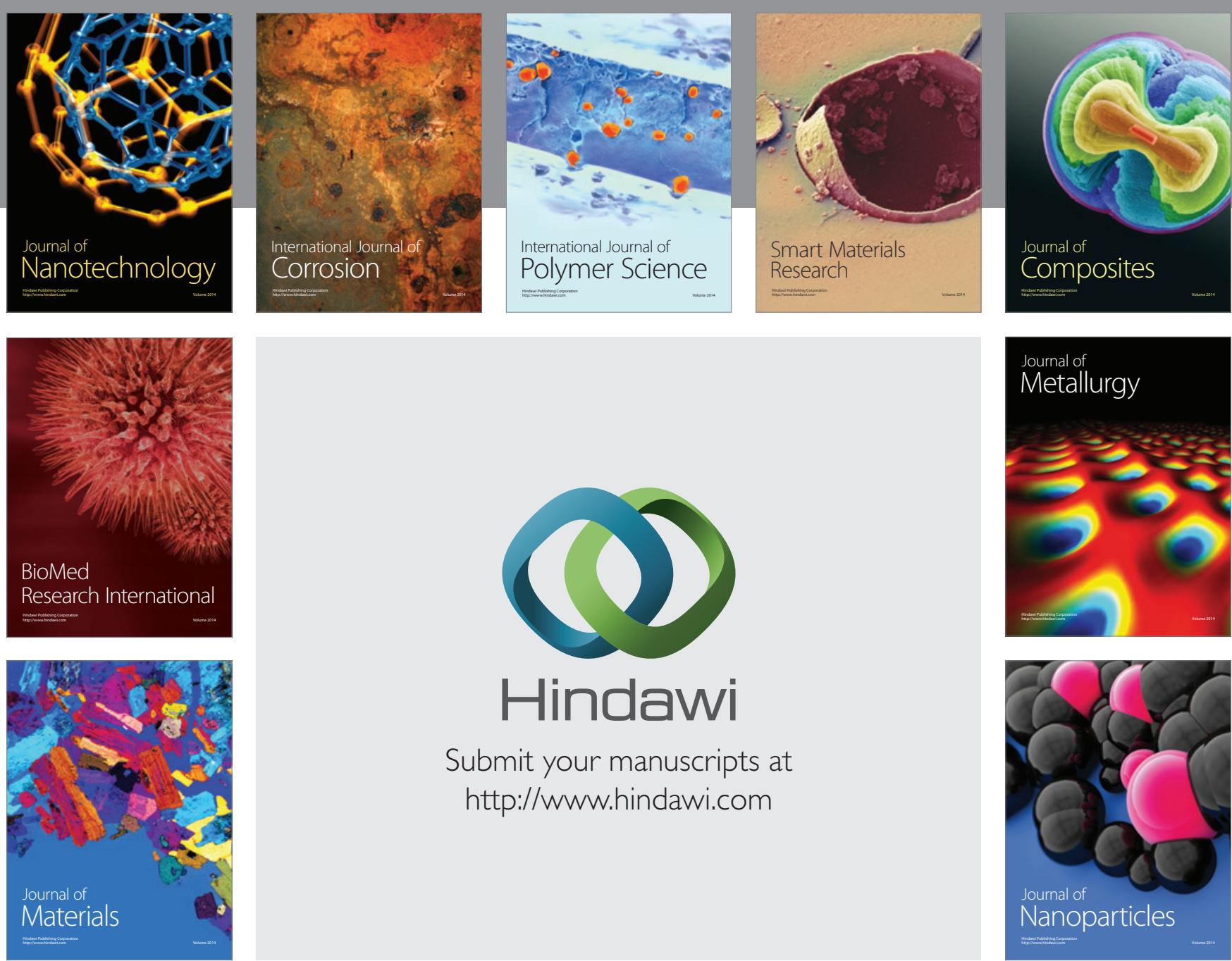

\section{Hindawi}

Submit your manuscripts at

http://www.hindawi.com

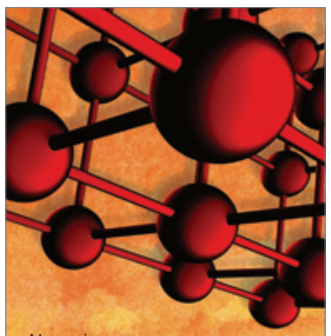

Materials Science and Engineering
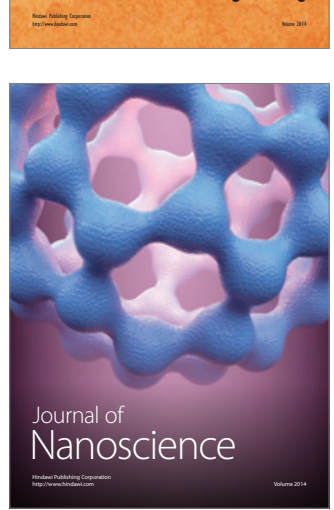
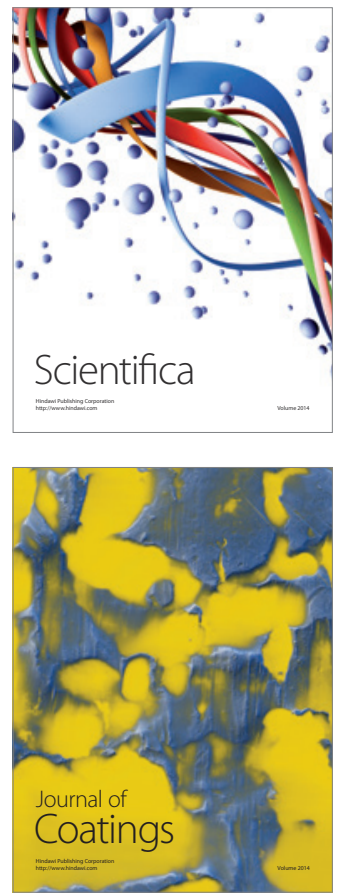
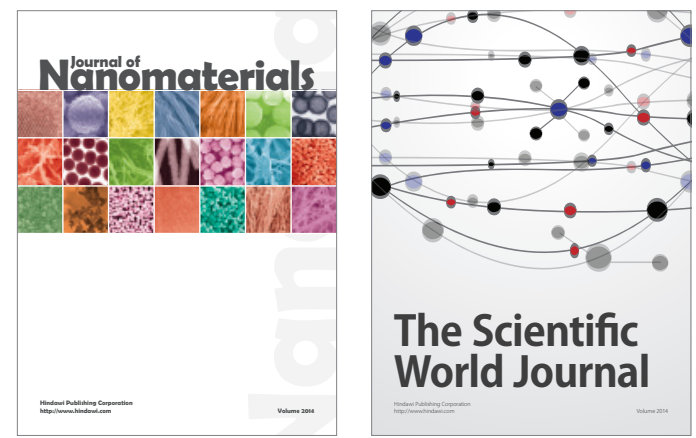

The Scientific World Journal
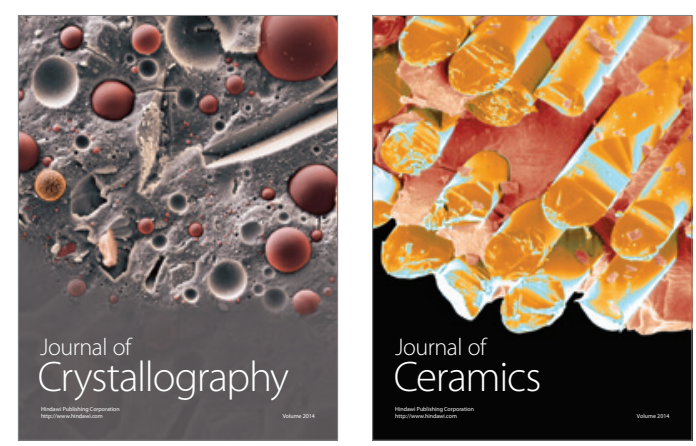
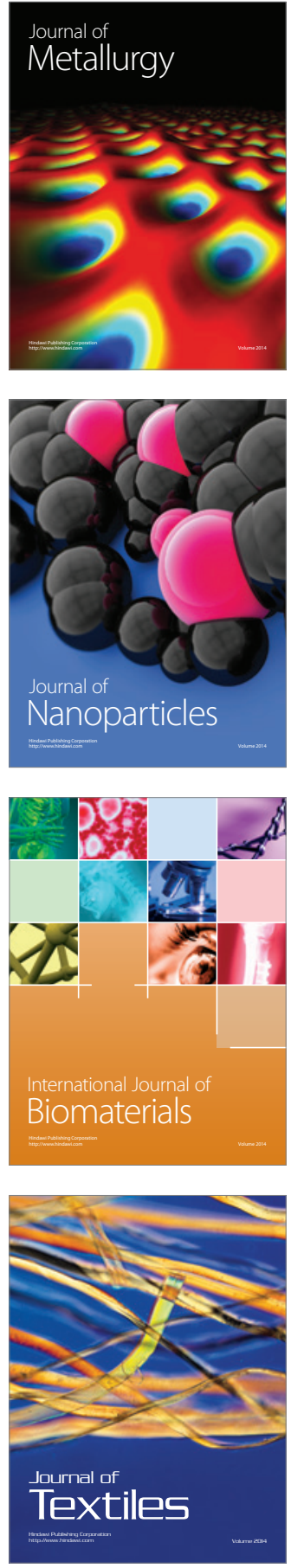